\title{
A Reforma curricular do Ensino Médio no Cepae SOB A PERSPECTIVA DOS ALUNOS
}

\author{
Andréa Ferreira Delgado, Danilo Rabelo, Elizabete Francisca de \\ Oliveira Pereira, Ivone Gomes de Santana Moura, Régis Henrique \\ dos Reis Silva e Wanderley Alves dos Santos*
}

\section{Resumo}

A reforma do Ensino Médio realizada no Centro de Ensino e Pesquisa Aplicada à Educaçáo é problematizada nesse artigo a partir da investigação da opinião dos alunos. Discutem-se as implicaçôes da escolha do questionário como instrumento de pesquisa, apresentam-se as questóes elaboradas e registram-se os dados obtidos. Com isso, desejamos conhecer e discutir os objetivos que os alunos apontam para o ensino médio, como eles analisam a oportunidade de compor seu próprio currículo e os critérios que orientam a escolha das disciplinas, suas percepçóes acerca do funcionamento da escola no turno vespertino e a forma como avaliam as disciplinas organizadas para o Núcleo Flexível do currículo.

Palavras-chave: ensino médio, reforma de ensino, currículo, alunos adolescentes.

The High School Curricular Reform in Cepae under the students perspective

Abstract

The High School Curricular Reform held in Cepae is problematized in this paper starting from the investigation of the students point of view. The implications of the choices in the questionnaire are discussed as a research tool. The questions in the questionnarie are presented and the collected data are recorded. Through this, we want to know and discuss the aims that the students point to High School; how they analyse the opportunity of choosing their own curriculum and the criterias that guide the choice of subjects; their perceptions about having classes in the afternoon and the way they assess the subject organization in the flexible curriculum.

KEY wORDs: High School, reform, curriculum, teenagers.

A implantação da reforma do Ensino Médio no Centro de Ensino e Pesquisa Aplicada à Educaçáo teve início em 2004. Concomitantemente, foi criada a Comissão de Implantação e Acompanhamento da Reforma do Ensino Médio, composta por um representante de cada Subárea do Cepae - que reúne os professores que ministram as disciplinas escolares - e coordenada pela professora Andréa Ferreira Delgado.

\footnotetext{
* Professores do Cepae/UFG, membros da Comissão de Implantação e acompanhamento da Reforma do Ensino Médio. E-mail: andreadelgado@uol.com.br.
} 
A nova estrutura curricular do Ensino Médio está organizada em dois turnos. No matutino funciona o Núcleo Básico com as disciplinas obrigatórias para todos os alunos: Português, História, Geografia, Matemática, Física, Química, Biologia, Educação Física, Artes, Espanhol e uma segunda Língua Estrangeira - Francês ou Inglês, de acordo com escolha realizada pelo aluno. No segundo ano há aulas de Filosofia e, no terceiro, de Sociologia. No turno vespertino os alunos cursam o Núcleo Flexível do currículo: no início do primeiro ano optam por uma das Áreas de Conhecimento - Biológicas, Exatas ou Humanas - e, entre as disciplinas ofertadas pelas Subáreas que compóem a Área escolhida, selecionam anualmente as "disciplinas acessórias obrigatórias" que desejam cursar. Além disso, dentre o conjunto das disciplinas ofertadas anualmente no Núcleo Flexível, os alunos escolhem as "disciplinas acessórias optativas" que querem cursar para complementar seu currículo.

Percebe-se, assim, que a característica fundamental da reforma é a construção do currículo pelo próprio aluno adolescente, em um exercício constante de autonomia, auto-conhecimento e responsabilidade (Delgado et. al., 2005).

A avaliação dessa reforma curricular foi uma das tarefas mais importantes desenvolvidas pela Comissão, tal como proposta pelas Diretrizes Curriculares Nacionais: a "diversificação do Ensino Médio deverá ser acompanhada de sistemas permanentes de avaliaçáo que permitam o acompanhamento permanente dos resultados" (Brasil / DCNEM, 2002b, p. 82).

Ao longo de três anos realizamos um trabalho de avaliação contínuo e sistemático envolvendo os docentes do Cepae e, em 2006, promovemos uma investigação para apreender como os alunos avaliam a organização curricular do Ensino Médio. A opinião dos pais foi analisada a partir de alguns dados do questionário elaborado pela Comissão de Reestruturação do Projeto Político-Pedagógico do Cepae, coordenada pela professora Maria Izabel Barnez Pignata, e aplicado aos pais dos alunos veteranos do Ensino Fundamental e Médio durante a matrícula para o ano letivo de 2006, com o objetivo de conhecer como esses pais avaliam o trabalho desenvolvido na escola.

Essa avaliação realizada pelos docentes, alunos e seus familiares subsidiou a decisão do Conselho Diretor do Cepae de manter os pressupostos fundamentais do atual currículo, reformulando alguns aspectos relativos à diminuição da carga horária e a oferta de disciplinas no Núcleo Flexível do currículo. 
Revista Solta a Voz, v. 18, n. 2137

Neste artigo, vamos problematizar o Ensino Médio do Cepae a partir da perspectiva dos alunos adolescentes, por meio da discussão dos resultados da investigação promovida por alguns membros da Comissão de Implantação e Acompanhamento da Reforma do Ensino Médio. A opção pela utilização de um questionário como instrumento de coleta de dados justifica-se pelo pouco tempo que tínhamos para realizar nossa tarefa e pelo desejo de conhecer a opinião dos 180 alunos que cursam o Ensino Médio, abandonando, por isso, a idéia de amostragem. Com isso, ao longo do artigo analisamos a opinião dos 168 alunos que compareceram às aulas no dia da aplicação do questionário.

\section{A METOdologia de CONSTRUÇáo do QUESTIONÁRIO}

Tal como observado na literatura, o processo de elaboração do instrumento de investigação é longo e complexo, visto que

[...] requer a observância de normas precisas, a fim de aumentar sua eficácia e validade. [...] O pesquisador deve conhecer bem o assunto [...] Exige cuidado na seleção das questóes, levando em consideração a sua importância, isto é, se oferece condiçôes para a obtenção de informaçôes válidas. Os temas escolhidos devem estar de acordo com os objetivos gerais e específicos. (Lakatos e Marconi, 2003, p. 202-203)

Nossos estudos iniciais concentraram-se no delineamento das categorias para a construção do instrumento da investigação e as alternativas para elaboração de questôes. Para isso, selecionamos a bibliografia a partir de dois eixos: primeiro, as implicaçôes teóricas e metodológicas decorrentes da utilização de questionário em pesquisas, além de aspectos pertinentes à construção desse instrumento; segundo, leituras na área dos estudos do currículo e estudo do documento "A reforma curricular do Ensino Médio" (Comissão do Ensino Médio do Cepae, 2004), elaborado pela Comissão do Ensino Médio para definir teórica e metodologicamente a reforma curricular implantada na instituição, a fim de nos auxiliar a delinear as categorias para a construção do questionário.

A metodologia de pesquisa compreendeu várias etapas: a) discussão coletiva para estabelecer as categorias que orientaram a elaboração das questóes e, também, o tipo de questôes; b) elaboração das questóes sob 
responsabilidade de três duplas; c) apresentação da primeira versão das questōes elaboradas pelas duplas, discussão e reelaboração coletiva das questóes; d) produção da primeira versão do questionário; e) entrevistas abertas com 10 alunos, com o objetivo de verificar tanto as questóes quanto a pertinência das alternativas propostas; $f$ ) revisão do questionário a partir das entrevistas; g) envio do questionário para a avaliação dos colegas da Comissão do Ensino Médio; h) pré-teste, com a aplicação do questionário para 10 alunos; i) avaliação do pré-teste e elaboração da versão final do questionário; j) revisão do questionário; $\mathrm{k}$ ) planejamento do processo de aplicação do questionário; l) aplicação do questionário nas seis turmas do Ensino Médio; m) tabulação dos dados; n) tratamento estatístico dos dados; o) análise e interpretaçáo dos dados obtidos; p) produção do relatório final.

$\mathrm{Na}$ construção do questionário estabelecemos uma ordem de perguntas a partir de núcleos temáticos fundamentais na nova organização curricular do Ensino Médio. Quanto à forma, optamos por perguntas fechadas, na maior parte de "múltipla escolha", "que apresentam uma série de possíveis respostas, abrangendo várias facetas do mesmo assunto" (Lakatos e Marconi, 2003, p. 206). No entanto, em várias perguntas combinamos respostas de múltipla escolha com as respostas abertas - os alunos podiam escrever para completar a alternativa "outros". No final do questionário, propusemos que os alunos tecessem um comentário sobre o questionário e sobre a reforma do Ensino Médio.

Procurávamos, com isso, além de captar informações perceptivas e opinativas (Thiollent, 1985), registrar o discurso dos alunos e buscar suas representaçóes acerca do nosso objeto de avaliação: o que eles pensam, como percebem, que opinióes formulam e que expectativas desenvolvem ao cursar o Ensino Médio tal como proposto na nova organização curricular do Cepae.

Em todos os momentos da elaboração do questionário estávamos atentos para a crítica epistemológica da técnica adotada que, conforme nos ensina Bordieu (1985), questiona a suposta neutralidade ou objetividade de qualquer opção metodológica de pesquisa. Preocupava-nos, principalmente, a imposição da problemática pelo questionário que, segundo Thiollent (1985, p. 48), consiste "no fato de colocar o entrevistado frente a uma estruturação dos problemas que não é a sua e no fato de estimular a produção de respostas que chamamos reativas". 
Não só a elaboração das perguntas, mas, principalmente, as alternativas propostas, exigiram que nos aproximássemos do universo dos adolescentes para evitar que limitássemos suas expressóes por meio de alternativas distanciadas dos significados que atribuem aos diversos componentes da reforma curricular. Com esse objetivo, depois de elaborada uma primeira versão do questionário, realizamos uma entrevista aberta com dez alunos, propondo as questóes que tínhamos elaborado sem, no entanto, predefinir a resposta. Assim, pudemos comparar as respostas obtidas com as alternativas que havíamos elaborado e reestruturar nosso instrumento de pesquisa. A próxima etapa foi a aplicação do pré-teste, para verificar a compreensão e a complexidade das questóes, a pertinência da linguagem utilizada, a adequação da ordem e a extensão das questôes aos objetivos da pesquisa, entre outros aspectos (Lakatos e Marconi, 2003).

Destacamos, nesse processo de elaboração do questionário, a discussão que realizamos com o Grêmio Estudantil para expor os objetivos do nosso trabalho e para convidá-los a nos ajudar, tal como efetivamente aconteceu nos dois momentos de consulta aos alunos - na entrevista aberta e no pré-teste. Ressaltamos a participação dos outros membros da Comissão de Implantação e Acompanhamento da Reforma do Ensino Médio que, além da colaboração inestimável prestada na tabulação dos dados, também contribuíram discutindo as etapas e conclusōes desse trabalho.

$\mathrm{Na}$ seqüência apresentaremos as questóes que compóem o questionário e as porcentagens de respostas assinaladas em cada uma das alternativas com o objetivo de expor e discutir as percepçóes dos alunos acerca do funcionamento da escola no turno vespertino e a organização curricular proposta para o Ensino Médio, seus objetivos ao cursá-lo, os critérios que os orientam na composição do currículo e a forma como analisam as disciplinas organizadas a partir da proposta pedagógica da reforma.

\section{O funcionamento do Ensino Médio no tURno vespertino:}

\section{a Reforma do Ensino MÉdio E a EXCLUSÃo/INCLUSÃo ESCOLAR}

As perguntas de 1 a 6 do questionário elaborado como instrumento de avaliação da reforma do Ensino Médio compreendem a análise dos alunos a respeito da organização do turno vespertino e da organizaçáo administrativa.

Ao serem questionados acerca dos "problemas enfrentados para permanecer na escola no turno da tarde", os alunos podiam assinalar mais de 
140 Revista Solta a Voz, v. 18, n. 2

uma alternativa: entre os 168 alunos que responderam ao questionário, 24,54\% dos estudantes assinalaram alimentação; $21,40 \%$ horário para estudar e fazer as tarefas das disciplinas escolares; $17,53 \%$ horário para atividades fora da escola; $14,76 \%$ espaço físico da escola para atender a alunos dos dois períodos; $8,30 \%$ impossibilidade de buscar emprego ou permanecer nele; $6,83 \%$ transporte; $4,43 \%$ problemas financeiros; $1,48 \%$ ausência de segurança; e 0,74\% nenhum problema.

Ao somar as alternativas que mostram as dificuldades dos alunos para permanecerem no turno vespertino, atinge-se um total de 99,3\%, enquanto a que aponta a inexistência de problemas foi assinalada por apenas $0,74 \%$. Assim, deve-se reconhecer que a organização do turno vespertino, sob a perspectiva dos alunos, dificulta sua permanência na escola.

Analisando os comentários tecidos pelos alunos acerca da reforma, os aspectos negativos apontados incidem, na maior parte, em torno das dificuldades para a permanência na escola: muitos reivindicam o fornecimento de almoço e de lanche, apontando dificuldades financeiras, enquanto outros solicitam armários para guardar seus materiais. Alguns alegam, também, que as aulas à tarde diminuem o tempo disponível para estudar e realizar as tarefas escolares ou impossibilitam a participação em cursos fora da escola. Alguns poucos reclamaram do turno vespertino porque precisariam trabalhar para auxiliar a família. Em geral, os alunos manifestaram-se no sentido de solicitar a diminuição da carga horária no turno vespertino.

As dificuldades acarretadas pela permanência do aluno no turno vespertino nos preocupavam desde o início das discussóes que cercaram a implantação da reforma, uma vez que esses problemas apontados influenciam o desempenho escolar dos alunos e, no limite, podem acarretar a evasão sob a forma de transferência para outra escola.

Por isso, além das questóes pedagógicas, outra ordem de questóes, associadas à cidadania, se impõe: a inclusão e a exclusão; a universalização que garante igualdade de direitos a todos e a legitimação de direitos como preocupaçôes que devem estar inseridas no cotidiano escolar.

Gadotti (2004, p. 57) ressalta como primeira condição de uma escola que se pretende cidadã: "Ser para todos e democrática na sua gestão, quanto ao acesso e permanência. Ter um caráter social comunitário, espaço do público para elaboração da sua cultura”.

Portanto, o Cepae será uma escola inclusiva quando garantir a universalidade e a permanência, além da qualidade de seu atendimento. 
A universalidade foi conquistada e legitimada pela forma de ingresso dos estudantes, ou seja, pelo sorteio de vagas. A permanência associa-se às políticas públicas que assegurem as condiçóes necessárias para o aluno ter acesso aos materiais didáticos, ao transporte, ao uniforme, à alimentaçáo e a outros aspectos que garantam a freqüência e auxiliem o aproveitamento escolar.

Trata-se, portanto, de articular o direito à educação com a democracia, a partir do princípio da afirmação e da expansão de novas práticas da cidadania. Coutinho (1997, p. 146) afirma que um dos conceitos que melhor expressa a democracia é de cidadania como a

[...] capacidade conquistada por alguns indivíduos, ou por todos os indivíduos, de se apropriarem dos bens socialmente criados, de atualizarem todas as potencialidades de realização humana abertas pela vida social em cada contexto historicamente determinado. [...] é resultado de uma luta permanente, travada quase sempre a partir de baixo, das classes subalternas, implicando um processo histórico de longa duração.

O autor acrescenta que a tendência à universalização da cidadania que caracteriza a modernidade está organicamente ligada à idéia de direitos como fenômenos sociais, resultado da história e de demandas que são formuladas por grupos sociais antes de serem promulgados em Constituição, Código, Regimentos e outros.

O acesso à educação é um bom exemplo, pois mesmo sendo "dever da família e do Estado", tal como registrado na Lei de Diretrizes e Bases da Educação Nacional (Brasil/PCNEM, 2002a), apenas o ensino fundamental é obrigatório e gratuito (Art. $4^{\circ}$., I), enquanto que a lei apenas aponta "a progressiva extensão da obrigatoriedade e gratuidade ao ensino médio" (Art. $4^{\circ}$., II). Essa distinção tem conseqüências no que se refere às questôes de assistência ao educando, pois a LDB prevê o atendimento apenas aos alunos do ensino fundamental, nos seguintes termos: "atendimento ao educando, no ensino fundamental público, por meio de programas suplementares de material didático-escolar, transporte, alimentação e assistência à saúde" (Art. 4\%., III).

Esses programas públicos são fundamentais para garantir a permanência do aluno na escola, e o fato de não contemplarem o Ensino Médio limita o caráter universal associado ao direito à educação. Na prática, isso 
significa que nossos alunos do Ensino Médio não têm direito à merenda. No Cepae tal fato sempre foi minimizado, no turno matutino, com a ajuda do Círculo de Pais e Mestres, que complementa os recursos da merenda destinada apenas aos alunos do Ensino Fundamental. No turno vespertino, porém, os alunos não recebem merenda.

Percebe-se, portanto, que a organização do Ensino Médio nos turnos matutino e vespertino pode configurar uma prática de exclusão se não conseguirmos atender às demandas geradas, como a da alimentação, por exemplo.

O termo exclusão, segundo Juncá (1996), tem passado por vários significados na realidade brasileira. Associada à desigualdade social, a exclusão se constrói como um resultado perverso do capitalismo brasileiro, a partir de um quadro de carências básicas, e culmina na exclusão econômica, social e política, em situações de fome, analfabetismo, subemprego, falta de habitação, escola, saúde, enfim, perda da dignidade humana e dos direitos sociais.

Sendo assim, a não-permanência na escola, provocada pelas condições sócio-econômicas das famílias que estáo impossibilitadas de atender às novas demandas colocadas pela permanência do aluno no turno vespertino, configura uma situação de exclusão, que precisamos minimizar promovendo o acesso aos serviços sociais existentes na Universidade Federal de Goiás - como, por exemplo, o acesso à isençáo ou a redução do valor cobrado no Restaurante Universitário.

Ao serem investigados sobre "o que, além das aulas, o turno da tarde propicia", os estudantes responderam: aprofundar seus conhecimentos (24,35\%); participação em atendimentos realizados pelos professores (16,52\%); estudos em grupo (10,43\%); utilização da biblioteca com mais freqüência (10,14\%); estudo individual $(5,22 \%)$; oportunidade para encontrar os colegas e fazer novas amizades $(16,52 \%)$, ampliação das atividades culturais (8,99\%); nada de importante $(6,09 \%)$; e outros $(1,74 \%)$. Ao todo, 345 alternativas foram assinaladas, pois a questão era de múltipla escolha.

Esta questão confirma que o turno vespertino facilita as oportunidades de estudo e de realizaçấo das tarefas das disciplinas escolares, além de propiciar o processo de socializaçáo dos adolescentes. Essa dimensão da escola como espaço da sociabilidade, foi destacada por Marques (1999, p. 95): 
Os jovens buscam na escola um espaço de sociabilidade e de troca de experiências que ultrapassam as dimensōes da simples, porém importante, busca de instrução. Daí sua capacidade de inverter, até pela própria incapacidade da escola, as funçóes para as quais ela foi criada. Os jovens conseguem transformar espaços estruturados por horários e atividades rígidas em espaços de descontração, criando redes de relaçóes sociais que ampliam sua sociabilidade.

Esse aspecto também pode ser observado na participação significativa dos alunos em atividades realizadas fora do espaço da sala de aula. Ao responderem à pergunta: "de quais atividades realizadas pela escola você participa?", os adolescentes responderam: atividades artísticas e culturais (40,24\%); atividades de ensino (22,31\%); atividades esportivas e recreativas (16,33\%); grêmio estudantil (5,28\%); $2,79 \%$ marcaram todas as alternativas citadas; e 12,75\% afirmaram que não têm "nenhuma participação".

O percentual das alternativas referentes à participação dos alunos nas atividades realizadas pela escola permite inferir que os alunos avaliam positivamente as atividades propostas pelos professores, seja no turno matutino ou vespertino.

Ao observar aquilo que os alunos afirmam que este turno lhes propicia, além das aulas, e, também, considerando a participação efetiva nas atividades oferecidas pela escola, pode-se inferir que eles percebem muitos aspectos positivos no funcionamento da instituição em período integral.

\section{A ORGANIZAÇÃo ADMINISTRATIVA}

A organização administrativa, sob a perspectiva dos estudantes, também foi investigada por meio da pergunta: "Quais as dificuldades que você enfrentou para realizar a sua matrícula nas disciplinas da tarde?”. Os alunos afirmaram: ausência de vagas nas disciplinas que queriam cursar, 33,23\%; choque de horário das disciplinas, 28,84\%; desorganização da escola no processo de matrícula, $11,60 \%$; orientação inadequada para a escolha das disciplinas no ato da matrícula, 9,72\%; insuficiência de informaçôes no caderno de apresentação das disciplinas, 6,90\%; inexistência de alguém para tirar dúvidas a respeito da nova organização do ensino médio, $3,13 \%$; e nenhuma dificuldade, $6,58 \%$.

O processo de matrícula é muito mais complexo do que aquele realizado anteriormente, no qual o aluno se inscrevia apenas em determinada 
144 Revista Solta a Voz, v. 18, n. 2

série. Na nova estrutura curricular, cada aluno vai compor seu currículo optando por um determinado conjunto de disciplinas ofertadas. $\mathrm{O}$ fato de $93,42 \%$ dos alunos apontarem problemas na matrícula nos leva a reconhecer falhas na estrutura administrativa e ressaltar que ter condiçóes materiais e humanas é requisito essencial para implantar uma reforma curricular. Vale ressaltar que ao longo desses três anos a coordenação do Ensino Médio tem tentado aprimorar constantemente o sistema de realização das matrículas e de produção dos boletins escolares dos alunos desta fase, esbarrando, também, em questóes operacionais decorrentes da ausência de informatização.

Em outra questão a respeito da organização administrativa da escol para atender a implantaçáo da reforma do ensino médio: "Qual a sua opiniāo sobre a coordenação do Ensino Médio?”, os alunos afirmaram que suas expectativas são atendidas parcialmente (45,93\%); não atende às suas expectativas (19,19\%); não têm opinião formada $(17,44 \%)$; não conhece as atribuições da coordenação $(9,30 \%)$; consideram que a coordenação do Ensino Médio atende totalmente às suas expectativas $(8,14 \%)$.

Diante desse conjunto de questōes, desde o início da reformulação do Ensino Médio em 2004, a Comissão, em parceria com a Coordenação, tem se preocupado em ampliar a discussão com os profissionais desta escola para, dentre outras possibilidades, criarem novas formas de organização do trabalho escolar e verificar questôes administrativas imprescindívei à implementação da reforma curricular, procurando novas formas de assistência aos alunos que auxiliem o acesso aos programas sociais de apoio à família, à alimentação, à educação complementar, legitimados pelo Estatuto da Criança e do Adolescente (ECA), a Lei de Diretrizes e Bases da Educação (LDB), o Regimento da UFG e do Cepae.

\section{O ALUNO E A CONSTRUÇÃo Do SEU CURRículo}

Um dos núcleos de elaboração do questionário produzido para investigar a opiniáo dos alunos acerca dessa reforma visa apreender a percepção dos adolescentes quanto aos objetivos do Ensino Médio, a avaliação que faz da proposta de construção do próprio currículo e os critérios que utiliza para escolher a Área de Conhecimento e as disciplinas optativas.

Questionados a respeito do seu principal objetivo ao cursar o Ensino Médio, entre os 168 alunos pesquisados, 79,86\% associaram-no 
com a continuidade dos estudos; $55,23 \%$ têm como principal objetivo a aprovação no vestibular; $10,45 \%$ esperam preparar-se para ingressar em cursos técnicos voltados ao mercado de trabalho; $14,18 \%$ assinalaram a alternativa "preparar para a continuidade dos estudos e para uma atuaçáo crítica e autônoma na sociedade". Apenas 4,10\% apontam o ingresso direto ao mercado de trabalho e 4,48\% cursam o Ensino Médio para "terminar a educação escolar básica”.

O Ensino Médio associa-se, prioritariamente, com a continuidade dos estudos, principalmente com o desejo de ingressar no ensino superior. Esse resultado é compatível com aquele obtido na pesquisa realizada por Maria Laura Franco e Gláucia Novaes (2001, p. 178) com jovens do Ensino Médio na cidade de São Paulo, na qual "observa-se, em 50\% dos casos, a crença de que a escola possibilitará melhores oportunidades de ser alguém na vida ou de ingressar no mercado de trabalho".

Observa-se coerência entre os objetivos apontados pelos alunos do Cepae e aqueles que fundamentam a reforma do Ensino Médio, visto que a formação intelectual do aluno visa tanto ao exercício da cidadania, fundamento do projeto político-pedagógico do Cepae, quanto à preparação para o prosseguimento dos estudos, seja no ensino superior ou técnico.

Quando solicitamos que os alunos manifestassem sua opinião a respeito da possibilidade de organizar seu próprio currículo, escolhendo a segunda língua estrangeira que irá cursar no Núcleo Básico, a Área de Conhecimento e as disciplinas optativas que desejam cursar para integralizar seu currículo, 79,65\% declararam-se favoráveis, sendo que, entre estes, $20,93 \%$ apontam dificuldades para a realização das escolhas. A porcentagem dos alunos desfavoráveis é de $9,3 \%$, igual à daqueles que assinalaram que não têm opinião.

Conclui-se que o aluno mostra-se disposto a assumir a construção do seu próprio currículo. Esse aspecto é central na avaliação da reforma, visto que constitui um dos fundamentos da organização curricular proposta. Exige-se do aluno a condição de protagonista do processo escolar (Ferreti; Zibes e Tartuce, 2004): o currículo passa a constituir espaço para a iniciativa (ação), para a liberdade (de fazer opçôes) e compromisso (responsabilidade por suas escolhas). Estimula-se a associaçáo entre aprendizagem e autonomia, uma vez que optar por determinadas disciplinas exige do aluno a tomada de decisóes a partir do auto-conhecimento intelectual, social e afetivo. 
Entre as dificuldades encontradas para organizar seu currículo os alunos destacaram problemas com o horário, $35,5 \%$, ausência de vagas nas disciplinas escolhidas, $30,92 \%$, e, ainda, o fato de desconhecer o conteúdo das disciplinas ofertadas, $10,31 \%$. Apenas $14,12 \%$ assinalaram a alternativa que enfatizava a insegurança: $7,25 \%$ porque não têm opinião formada a respeito da Área na qual gostaria de se aprofundar; 3,05\% têm a mesma dificuldade ao escolher as disciplinas optativas que desejam cursar; e 3,82\% estão inseguros tanto para escolher a Área de Conhecimento quanto para eleger suas disciplinas optativas. No conjunto dos alunos, $8,4 \%$ afirmaram não encontrar nenhuma dificuldade.

Conclui-se que, na perspectiva dos adolescentes, as maiores dificuldades encontradas na montagem do currículo decorrem de situaçóes que fogem ao seu controle e que podem ser melhor planejadas pela Coordenação no Ensino Médio. Ao mesmo tempo, menos de 15\% revelam sentir insegurança ao realizar essa tarefa. Cabe, então, investigar quais os critérios que os alunos utilizam para optar por uma Área de Conhecimento no final da oitava série e para escolher anualmente as disciplinas optativas.

Uma conclusão impóe-se imediatamente: a perspectiva dos alunos de associar o Ensino Médio ao vestibular manifesta-se na construção da parte flexível do currículo, visto que 49,47\% escolheram a Área de Conhecimento pensando no processo seletivo, $13,68 \%$ a Área composta pelas disciplinas em que encontram dificuldades, mas que consideram importantes para o vestibular e $35,79 \%$ associam a escolha com a profissão que pretendem exercer. Nesse grupo, acrescentam-se ainda $27,02 \%$ dos alunos que assinalaram a alternativa "afinidade com as disciplinas" para justificar sua opção.

Podemos concluir, portanto, que $76,49 \%$ dos alunos declararam que a escolha das disciplinas obrigatórias está relacionada com sua trajetória pessoal, demonstrando que desejam, desde cedo, aprofundar seus conhecimentos e habilidades nas áreas de conhecimento com as quais, ao longo da prática social e escolar, foram identificando-se, delineando, assim, um caminho de escolha profissional.

Outros critérios foram, ainda, minoritariamente assinalados pelos alunos para justificar a escolha pela Área de Conhecimento: as disciplinas são fáceis, 7,02\%; o horário das disciplinas, 7,02\%; acompanharam a escolha de amigos, 4,91\%; "gosto dos professores que ministram as disciplinas da Área de Conhecimento", 2,81\%. 
No momento de escolher as disciplinas optativas diminui a preocupação com o vestibular, embora esse seja relevante para $27,68 \%$ dos alunos: $11,31 \%$ escolheram como optativas aquelas em que encontram dificuldades, mas que julgam importante para o processo seletivo, 16,37\% as associaram com a escolha profissional. A porcentagem daqueles que tem como principal critério a afinidade com a disciplina mantêm-se em patamar próximo aos que assinalaram a mesma alternativa quanto a Área de Conhecimento: 20,54\%.

Em contrapartida, aumenta a porcentagem daqueles que escolhem as disciplinas optativas devido ao horário, 13,69\%, e em função dos amigos, $7,44 \%$. Também nas optativas o professor não influencia muito a escolha das disciplinas, $2,68 \%$, e cai ainda mais a porcentagem daqueles que optam pelas fáceis, $6,55 \%$. Em resumo, são $30,36 \%$ que não consideram a afinidade e nem a continuidade dos estudos ao escolherem suas disciplinas optativas.

Vale investigar a relação que os alunos estabelecem entre a Área de Conhecimento e as disciplinas optativas: 10,42\% escolhem as disciplinas optativas ofertadas pelas mesmas Subáreas que compóem sua Área de Conhecimento, enquanto que $9,82 \%$ procuram escolher as de outras. Se agregarmos a porcentagem daqueles que declaram ter afinidade com as disciplinas optativas, $20,54 \%$, e dos que demonstram a preocupação com o vestibular e com a profissão, $27,68 \%$, podemos afirmar que $48,22 \%$, ao elegerem, mantêm critérios semelhantes àqueles que orientam a opção pela Área de Conhecimento, procurando compor o currículo de acordo com seus interesses, habilidades e aptidóes.

Há, portanto, uma noção de complementaridade entre os critérios de escolha da Área de Conhecimento e das disciplinas optativas. Isso significa que o adolescente, ao construir seu currículo, tece sua própria rede de conhecimentos a partir, principalmente, de escolhas conscientes e responsáveis, fundamentadas no conhecimento de suas características pessoais e aspiraçôes profissionais.

\section{O CURRÍCULO EM AÇÃo}

A terceira parte do questionário respondido pelos alunos do Ensino Médio compreende uma avaliação do "currículo em ação", compreendido, na acepção de Moreira (2003), como o lugar onde os alunos se posicionam 
a respeito das disciplinas acessórias e do Núcleo Básico, analisando a metodologia e a especificidade da parte flexível da organização curricular.

Ao serem perguntados se "as disciplinas acessórias (turno vespertino) têm apresentado algum tipo de relação entre duas ou mais disciplinas (interdisciplinaridade)", 25,9\% dos alunos responderam que sim, 19,88\% não, $44,58 \%$ disseram que às vezes e $9,64 \%$ não sabiam responder. Ao todo 166 alunos responderam a esta questão, ou seja, dois alunos não se manifestaram.

O currículo organizado para o Ensino Médio no Cepae, ao estabelecer as Áreas de Conhecimento e estimular práticas interdisciplinares para a criação das disciplinas no Núcleo Flexível, fundamentou-se na "reunião daqueles conhecimentos que compartilham objetos de estudo e, portanto, mais facilmente se comunicam, criando condiçóes para que a prática escolar se desenvolva numa perspectiva de interdisciplinaridade" (Brasil/PCNEM, 2002c, p. 32).

Considerando-se a soma das respostas positivas sobre a prática da interdisciplinaridade nas disciplinas acessórias, isto é, os itens "sim" e "às vezes", temos o significativo percentual de $70,48 \%$. Entretanto, deve-se reconhecer que a interdisciplinaridade no Ensino Médio do Cepae está apenas se iniciando, haja vista que $44,58 \%$ dos alunos reconhecem que ela acontece apenas esporadicamente.

De fato, ao se verificar as ementas das 86 disciplinas acessórias oferecidas no triênio 2004-2006, constatamos que apenas cinco se constituíram como projetos interdisciplinares, isto é, como interação entre duas ou mais áreas do conhecimento. Dentre essas cinco, três disciplinas pertenciam às áreas de Ciências Humanas e Comunicação, articulando a interação entre Sociologia e Geografia; Filosofia e Redação; História e Literatura. As demais promoviam a interação entre Biologia e Química.

Por outro lado, todas as disciplinas oferecidas enfatizavam, em suas ementas, a contextualização a partir da seleção de conteúdos significativos para os alunos no desenvolvimento de competências e habilidades, bem como a utilizaçáo dos conhecimentos da área de Ciências Humanas para que esta ocorresse. Do mesmo modo, seis disciplinas eram de caráter multidisciplinar, isto é, a partir da contextualização de seus conteúdos e metodologias enfatizavam, em suas ementas, o diálogo entre diferentes ramos do conhecimento. Alguns exemplos podem ser citados: Inglês-Artes, Espanhol-Artes, MatemáticaEconomia, História-Literatura-Sociologia e Biologia-Ciências Humanas. 
Por diferentes caminhos tenta-se efetivar a interdiciplinaridade como uma das premissas pedagógicas do currículo do Ensino Médio, em consonância com as orientaçôes dos Parâmetros Curriculares Nacionais para esta fase: "a proposta da interdisciplinaridade é estabelecer ligaçôes de complementaridade, convergência, interconexóes e passagens entre os conhecimentos" (Brasil/PCNEM, 2002c, p. 26).

A questão seguinte está relacionada à anterior e foi assim escrita: "Caso a resposta dada na questáo anterior seja sim ou às vezes, avalie esta relação estabelecida entre as disciplinas, conforme os critérios a seguir". $62,77 \%$ avaliariam essa relação como positiva; $5,84 \%$ como negativa; $13,87 \%$ avaliaram como indiferente; $13,14 \%$ não possuíam uma opinião formada; e 4,38\% não responderam à questão. 131 alunos responderam a esta questão, ou seja, 37 alunos deixaram de contestá-la, demonstrando dificuldades em se posicionar sobre o assunto.

Nesta avaliação dos alunos quanto à interdisciplinaridade percebe-se, também, que uma significativa maioria considera a interação entre duas ou mais disciplinas como benéfica à sua formaçáo intelectual e escolar. Por outro lado, quase um terço, $31,32 \%$, se manifestaram como indiferentes, sem opinião formada ou não responderam sobre a importância de um ensino interdisciplinar na sua formação escolar. Há que se considerar, então, que a preocupação com a interdisciplinaridade pertence mais aos professores que aos alunos, embora grande parte deles tenha uma opinião formada sobre esse assunto.

Aos alunos também foi perguntado se "as aulas das disciplinas acessórias (da tarde) são diferentes das disciplinas do Núcleo Básico (da manhã)". As respostas foram assim distribuídas: $41,92 \%$ assinalaram positivamente; $12,57 \%$ negativamente; $\mathrm{e} 45,51 \%$ às vezes.

Sobre a especificidade das disciplinas acessórias, ao se somarem as respostas da questão que afirmam essa diferença, ou seja, os itens "sim" e "às vezes", obtém-se o percentual de $87,43 \%$. A natureza dessa especificidade será analisada adiante.

Outra questão, também relacionada à questão anterior, sondava a intensidade da diferença entre as disciplinas acessórias e as do Núcleo Básico: "Caso a resposta da questão dada na questão anterior, seja "sim" ou "às vezes", avalie esta diferença estabelecida entre as disciplinas, conforme os critérios, a seguir". As respostas assinaladas apresentaram o percentual de 22,92\% para "muito diferente"; 63,19\% para "pouco diferente"; e 13,89\% para "quase nada diferente". 
Desse modo, embora reconheçam quehaja diferençasentre as disciplinas acessórias e as do Núcleo Básico, os alunos afirmam que essa especificidade não se apresenta significativa, haja vista que a somatória dos itens "pouco diferente" e "quase nada diferente" perfaz o total de 77,08\%. Entretanto, a baixa intensidade na percepção das diferenças entre as disciplinas acessórias e as do Núcleo Básico já se encontrava implícita na questão anterior, uma vez que o item "às vezes" obteve o maior percentual, $45,51 \%$. Outro aspecto precisa ser avaliado: 144 alunos responderam a esta questão, estimulando a reflexão acerca dos motivos que levaram 24 deles a deixar de respondê-la.

Quanto às diferenças entre as disciplinas do Núcleo Básico e as acessórias, o questionário fez a seguinte solicitação aos alunos: "Caso você perceba diferenças nas disciplinas acessórias (da tarde), assinale as alternativas que representam esta situação". A freqüência das alternativas apresentou os seguintes percentuais: $12,96 \%$ para estratégias didáticas diversificadas; $14,20 \%$ para aulas criativas e interessantes; $9,88 \%$ para recursos tecnológicos (datashow, retroprojetor, vídeo, utilização delaboratório); 6,79\% paraprocesso avaliativo diferente; $4,94 \%$ para ensino por projetos e pesquisa; $10,19 \%$ relaçáo professor-aluno diferente; $17,59 \%$ para conteúdo aprofundado; 20,68\% para turmas compostas por alunos de diversas séries; $2,47 \%$ para questionários sem resposta nesta questão; e $0,31 \%$ para "outros".

Somente o item "Turmas compostas por alunos de diversas séries" obteve um percentual acima de $20 \%$. Por se tratar de uma questáo de múltipla escolha que esclarece a natureza da diferença entre as disciplinas acessórias e as do Núcleo Básico, pode-se inferir que os percentuais baixos em cada item desta questão também esclarecem porque os alunos pouco percebem essa diferença.

Para compreender esses dados, devemos lembrar que os fundamentos legais que orientam a flexibilizaçáo do currículo apontam como objetivo da parte diversificada da estrutura curricular atender "as possibilidades de preparaçáo básica para o trabalho e o aprofundamento em uma disciplina ou uma área, sob forma de disciplinas, projetos ou módulos em consonância com os interesses dos alunos e da comunidade a que pertencem" (Brasil/PCNEM, 2002c, p. 36). Assim, a baixa percepçáo das diferenças entre disciplinas acessórias também poderia ser explicada não só pela variedade de modalidades e metodologias de ensino, como também por se tratar de aprofundamento de uma disciplina ou área de conhecimento já pertencente ao Núcleo Básico. Por fim, os PCN’s do Ensino Médio (2002c, p. 34-36) também esclarecem que: 
Revista Solta a Voz, v. 18, n. 2151

$\mathrm{Na}$ perspectiva escolar, a interdisciplinaridade não tem a pretensão de criar novas disciplinas ou saberes, mas de utilizar os conhecimentos de várias disciplinas para resolver um problema concreto ou compreender um determinado fenômeno sob diferentes pontos de vista. Em suma, a interdisciplinaridade tem uma função instrumental. Trata-se de recorrer a um saber diretamente útil e utilizável para responder às questôes e aos problemas sociais contemporâneos.

Nesse sentido, os Projetos de Ensino das Subáreas do Cepae, elaborados em 2004, enfatizaram as especificidades de cada disciplina quanto à sua epistemologia, teorias, metodologias e relaçóes com o ensino escolar. Ao mesmo tempo, há um outro traço comum: a defesa da educação contextualizada, conforme as orientaçóes dos Parâmetros Curriculares do MEC e das Diretrizes do Conselho Nacional de Educação para o Ensino Médio.

Nos referidos projetos de ensino não houve uma tentativa de esclarecer a especificidade das disciplinas acessórias em relação às disciplinas do Núcleo Básico, e Artes Visuais, Biologia, Educação Física, História e Sociologia mencionaram brevemente que a interdisciplinaridade era contemplada na estruturação dos mesmos. Ao serem elaborados concomitantemente ao início da implantação da Reforma Curricular do Ensino Médio, os projetos de ensino não contemplaram detalhadamente a especificidade das disciplinas acessórias em relação àquelas do Núcleo Básico e pouco mencionaram a respeito da interdisciplinaridade, embora tenham discutido a contextualização e a formação de competências e habilidades.

Em suma, os projetos de ensino do Cepae consideram prioritariamente os objetos, as teorias e as metodologias próprias de cada disciplina como saber científico e sua transposição para a educação escolar. A ausência de discussão sobre a especificidade do Núcleo Básico em relação à parte diversificada do currículo do Ensino Médio, na qual a interdisciplinaridade deveria ser vista como metodologia de ensino para a aquisiçáo de competências e habilidades, é compreensível se levarmos em conta a argumentação de Élio Carlos Ricardo (2005, p. 203-204):

Assim, a ansiedade por vencer a suposta fragmentação dos saberes disciplinares apelando para a interdisciplinaridade não poderá se reduzir a uma simples justaposiçáo ou a uma utopia unificadora que desconsidere a autonomia da produção científica e descaracterize seu objeto e seus procedimentos. Delimitar um objeto de investigação não significa necessaria- 
152 Revista Solta a Voz, v. 18, n. 2

mente fragmentá-lo, desde que os aspectos históricos que o constituem não sejam esquecidos. É justamente a natureza complexa do objeto e seu caráter dialético que exige limites para a investigação. Esta, todavia, deverá superar o reducionismo e o apego cego ao empirismo.

A especialização, ou a fragmentação, vista como um mal em si, é tão equivocada como a compreensão de que a interdisciplinaridade seria uma solução em si.

A argumentação acima talvez possa explicar porque aproximadamente $47 \%$ dos alunos entrevistados não consideraram a interdisciplinaridade benéfica ou não tinham uma opinião formada sobre ela na sua formação escolar, afinal, a divisão em campos disciplinares tradicionais está consolidada na instituição escolar e, como afirma Santomé (1998, p. 61), "para que haja interdisciplinaridade é preciso que haja disciplinas".

Entretanto, durante o ano de 2005 os professores do Cepae discutiram a interdisciplinaridade como pressuposto pedagógico do novo currículo do Ensino Médio, especialmente nas disciplinas acessórias do Núcleo Flexível, por meio de reunióes e de um seminário sobre esse assunto. Como resultado desse processo, cada Subárea produziu um texto, refletindo sobre sua proposta pedagógica para o Ensino Médio e articulando o Núcleo Básico com as disciplinas acessórias, registrados no documento "O processo de avaliação da reforma curricular do Ensino Médio (2004-2006)" (Comissão do Ensino Médio, 2006).

No texto elaborado pela Comissão (2004, p. 17) para fundamentar a reforma curricular, apresenta-se assim a implantação da interdisciplinaridade:

$\mathrm{Na}$ implantação da reforma, pretendemos que as Áreas de Conhecimento sejam as instâncias de proposição das disciplinas acessórias obrigatórias, pois o currículo deve ser trabalhado de forma interdisciplinar a fim de romper com o tratamento compartimentalizado do conhecimento escolar. As disciplinas acessórias optativas, por sua vez, podem configurar experiências interdisciplinares entre as Áreas.

Assim como Ricardo (2005), o texto da Comissão do Ensino Médio do Cepae (2004, p. 18) não considera a interdisciplinaridade como panacéia que poderia solucionar os problemas que levam ao fracasso escolar:

A interdisciplinaridade não pode ser imposta ao corpo docente mediante a mudança curricular. Ao contrário, conforme Nogueira (1994: 74), 
a integração interdisciplinar ocorre através de processos, através do delineamento de rumos que busquem a "aventura construtiva que é o conhecimento", potencializando a contribuição de cada ciência para o conhecimento, a compreensão e a intervençáo na realidade social.

Desse modo, a especificidade das disciplinas acessórias e sua organização interdisciplinar estão sendo paulatinamente construídas na Reforma Curricular do Ensino Médio do Cepae. Trata-se, pois, de um processo gradual e, por isso mesmo, a especificidade de tais disciplinas e sua organização em projetos interdisciplinares são ainda incipientes.

Não obstante, a oferta de disciplinas acessórias tem um crescimento significativo a cada ano. Em 2004 foram oferecidas 12 disciplinas, no ano seguinte, 30, e, em 2006, 44 disciplinas. Possivelmente, um número menor de disciplinas poderia facilitar o crescimento do número de projetos interdisciplinares, porém, isso também poderia limitar as opções de escolha dos alunos para complementar seu currículo e para conciliar seus horários.

Ao final do questionário, foi solicitada aos alunos uma avaliação qualitativa do ensino das disciplinas do Núcleo Básico ministradas pela manhã. As respostas foram as seguintes: $14,88 \%$ assinalaram que o ensino era ótimo; $60,12 \%$ que era bom; $22,02 \%$ regular; $2,38 \%$ ruim; e $0,31 \%$ péssimo. Todos os alunos responderam a esta questão.

Além da avaliação acima, também foi solicitada uma avaliação qualitativa do ensino das disciplinas acessórias. As respostas apresentaram os seguintes percentuais: $10,18 \%$ ótimo; $37,13 \%$ bom; $32,93 \%$ regular; $10,18 \%$ ruim; e $9,58 \%$ péssimo.

Ao compararmos os índices das duas últimas questóes percebemos que, na aprovação geral do Ensino Médio no Cepae, a partir das respostas de seus alunos, as disciplinas do Núcleo Básico obtiveram percentuais bem superiores aos das acessórias. Nas representações dos alunos o Núcleo Básico obteve o percentual de aprovação de $75 \%$ (somatória dos itens "ótimo" e "bom"), enquanto que as disciplinas acessórias obtiveram o percentual de 47,31\% (somatória dos itens “ótimo" e "bom”). Além disso, o item "péssimo" apresentou o índice de 0,31\% para o Núcleo Básico e 9,58\% para as disciplinas acessórias.

Tal discrepância nos resultados talvez possa ser explicada por uma possível resistência à mudança curricular em curso, bem como pelas respostas assinaladas na primeira questão, que tratou das dificuldades que o 
aluno enfrenta para permanecer na escola no turno vespertino, embora a maioria dos alunos afirme que as disciplinas acessórias pouco ou quase nada diferem das do Núcleo Básico.

As reflexôes que desenvolvemos até aqui poderiam ser complementadas com uma análise dos comentários elaborados pelos alunos no final do questionário, porém, os limites deste artigo nos impedem de fazê-la. Entretanto, gostaríamos de encerrar com exemplos dos discursos dos alunos que demonstram bem a diversidade das avaliações que registramos e nos incitam a continuar enfrentando os complexos desafios impostos cotidianamente no nosso trabalho de educadores:

[1]

Mais que simplesmente "compor" informaçóes pro vestibular - que parece ser o grande objetivo da maioria dos alunos - as disciplinas acessórias servem para até mesmo formar um indivíduo, pois ele passa a maioria de seu tempo na escola, e os meios abordados para o ensino dessas disciplinas é interessante e produtivo, desde que haja interesse também do aluno. Pra melhorar o aprendizado era necessário tirar dos alunos a idéia de que se estuda unicamente para passar no vestibular. $\mathrm{O}$ ensino vai muito além do lucro para exercer bem determinada profissáo. $\mathrm{O}$ ensino forma a sociedade, e isso deve ser levado em primeiro plano.

[2]

Essa reforma foi imposta aos alunos e acho isso um ponto negativo, conheço vários alunos que tiveram que deixar a escola por não ter condiçóes de se manter estudando à tarde, pois muitos trabalham para ajudar no sustendo da família. Já que o Cepae luta e ensina seus alunos a lutarem por uma sociedade mais democrática e igualitária e com oportunidades para todos, penso então que é hora de rever os princípios ensinados. Eu vou deixar a escola no meio deste ano, pois náo tenho condiçốes de permanecer, e aí, onde está a comunidade cepaneana? Onde está a oportunidade de boa educação para todos?

[3]

Gostaria de saber quem propôs essa reforma pois só vejo essa bosta de aula a tarde no aplicação, essa reforma foi uma falta de respeito pois tira a vida particular do aluno queria fazer algum curso trabalhar mais não posso pelo fato de ter aula de tarde, tem gente que fala "pelo menos vc ta aprendendo". Tamo aprendendo nada venho aqui só para "cumprir carga”. 
[4]

A reforma do Ensino Médio, além de me propiciar uma visão ampla da realidade de determinadas áreas de conhecimento, me ajudou à compreender um pouco melhor o sistema de grade curricular de faculdades, trabalhando assim, minha autonomia e minha auto-estima. Só tenho a agradecer à esse colégio que trabalha o ser humano como alguém perante à uma sociedade, e não somente como máquinas de aprovação em vestibulares, como instrumentos publicitários.

\section{REFERÊNCIAS}

BRASIL. Lei de Diretrizes e Bases da Educação Nacional. In: Parâmetros Curriculares Nacionais: Ensino Médio. Brasília: MEC/SEMTEC, 2002a.

. Ministério da Educação. Conselho Nacional de Educação. Diretrizes Curriculares Nacionais para o Ensino Médio. In: Parâmetros Curriculares Nacionais: Ensino Médio. Brasília: MEC/ SEMTEC, 2002b.

. Ministério da Educação. Secretaria de Educação Média e Tecnológica. Parâmetros Curriculares Nacionais: Ensino Médio. Brasília: MEC/ SEMTEC, 2002c.

BORDIEU, P. A opinião pública não existe. In: THIOLLENT, M. (Org.). Critica metodológica, investigação social e enquete operária. São Paulo: Polis, 1985. p. 137-151.

CENTRO DE ENSINO E PESQUISA APLICADA À EDUCAÇÃO. Projetos de Ensino: Subáreas de Biologia, Física, Matemática e Química. Goiânia: Cepae, 2004a (mimeo).

CENTRO DE ENSINO E PESQUISA APLICADA À EDUCAÇÃO. Projetos de Ensino: Área de Filosofia, Geografia, História e Sociologia. Goiânia: Cepae, 2004b (mimeo).

Projetos de Ensino: Artes, Educação Física, Língua Portuguesa e Línguas Estrangeiras. Goiânia: Cepae, 2004c (mimeo).

COMISSÃO DO ENSINO MÉDIO DO CEPAE. A Reforma Curricular do Ensino Médio. Goiânia: Cepae, 2004 (mimeo).

O processo de avaliaçáa da reforma curricular do Ensino Médio (2004-2006). Goiânia: Cepae, 2006 (mimeo). 
156 Revista Solta a Voz, v. 18, n. 2

COUTINHO, C. N. Notas sobre cidadania e modernidade. Revista Praia Vermelha, v. 1, p. 145-165, 1997.

DELGADO, A. et al. A reforma do Ensino Médio no CEPAE. Revista Solta a Voz, v. 16, n. 2, p. 109-123, jul/dez. 2005.

FERRETI, C.; ZIBAS, D.; TARTUCE, G. Protagonismo juvenil na literatura especializada e na reforma do ensino médio. Caderno de Pesquisa, v. 34, n. 122, p. 411-423, mai./ago. 2004.

FRANCO, M. L. P. B.; NOVAES, G. T. F. Os jovens do ensino médio e suas representaçóes sociais. Caderno de Pesquisa, n. 12, p. 67-83, março 2001.

GADOTI, M. Escola cidadã. São Paulo: Cortez, 2004.

JUNCÁ, D. C. M. de. Ilhas de exclusão: o cotidiano dos catadores de lixo de Campos. Serviço Social \& Sociedade, ano XVII, n. 52, p. 106-126, 1996.

LAKATOS, E. M.; MARCONI, M. de A. Fundamentos de metodologia científica. São Paulo: Atlas, 2003.

MARQUES, M. O. da S. Juventude, escola e sociabilidade. In: PIMENTA, S. G. (Org.). Saberes pedagógicos e atividade docente. São Paulo: Cortez, 1999. p. 83-120.

MOREIRA, A. F. B. Currículo, utopia e pós-modernidade. In:

(Org.). Currículo: questóes atuais. Campinas: Papirus, 2003. p. 9-28.

RICARDO, E. C. Competências, Interdisciplinaridade e Contextualização: dos Parâmetros Curriculares Nacionais a uma compreensão para o ensino das ciências. 2005. Tese (Doutorado em Educação Científica e Tecnológica) - PPGECT, Universidade Federal de Santa Catarina, Florianópolis, 2005.

SANTOMÉ, J. T. Globalização e Interdisciplinaridade: o currículo integrado. Porto Alegre: Artes Médicas, 1998.

THIOLLENT, M. (Org.). Crítica metodológica, investigação social e enquete operária. Sáo Paulo: Polis, 1985. 